\title{
MIL ROSAS ROUBADAS, DE SILVIANO SANTIAGO, EM PERSPECTIVA BAKHTINIANA
}

\section{MIL ROSAS ROUBADAS, WORK OF SILVIANO SANTIAGO: A BAKHTINIAN ANALYSIS}

\author{
Renata Coelho Marchezan* \\ Universidade Estadual Paulista, Araraquara, SP, Brasil \\ Fuscelino Pernambuco** \\ Universidade de Franca, Franca, SP, Brasil
}

\begin{abstract}
Resumo: Neste estudo, propõe-se andisar Mil rosas roubadas, obra de Silviano Santiago de 2014, e, para tanto, ocupa-se das noç̃os de (auto)biografia, romance (auto)biográfico, metaficção e autoficção. Embora a criação deste último termo possa indicar a existência de um novo gênero - é, inclusive, adotado pelo próprio escritor para nomear sua obra,- 0 artigo mostra a pertinência de situar Mil rosas roubadas na rota das transformacçōes e estilizaçõoes do romance (auto)biográfico, tal como examinada e apontada por M. Bakhin. Para esse estudioso, o romance, gênero sem forma rígida e sempre inacabado, acompanha as inflexões da vida social. É, nesse caminho, que se analisa a ressemantização do ev, elaborada por Silviano Santiago.
\end{abstract}

Palavras-chave: Silviano Santiago; Bakhin; romance (auto)biográfico; metaficção; autoficção.

\begin{abstract}
This article analyzes Mil rosas roubadas, written by Silviano Santiago in 2014, dealing with the notions of (auto) biography, (auto)biographical novel, metafiction and autofiction. Although the creation of this last word may indicate the existence of a new genre - it is even adopted by the writer himself to name his work -, the article shows the pertinence of placing Mil rosas roubadas in the route of the transformations and stylisations of the (auto)biographical novel, such as examined by M. Bakhtin. The novel is, for Bakhtin, a genre without rigid forms, an unfinished genre, as it always follows the inflections of social life. In this way the ressemantization of the self, proposed by Silviano Santiago, is analyzed.
\end{abstract}

Keywords: Silviano Santiago; Bakhtin; (auto)biographical novel; Metafiction; Autofiction.

\footnotetext{
* Doutora da Universidade Estadual Paulista - UNESP, Araraquara, SP, Brasil; renata_marchezan@uol.com.br

* * Doutor da Universidade de Franca - UNIFRAN, Franca, SP, Brasil; juspernam@gmail.com
} 
Ao escrever não estou na vida. Estou na escrita. É meu modo de vida.

\section{K. O. Knausgard}

\section{Introdução}

O dialogismo, termo pelo qual se reconhecem as contribuições de M. Bakhtin e seu Círculo para o estudo da linguagem, e para as ciências humanas, tem em seu cerne o diálogo, entendido em sentido amplo, que recobre as relações eu/outro estabelecidas no mundo da vida e no mundo da cultura.

Desde seus primeiros textos e na maior parte de sua reflexão, Bakhtin ocupa-se da literatura, da arte. No entanto, em perspectiva filosófica, o ato criador e o autor-criador na arte são considerados, por ele, tanto em relação com a ética e o conhecimento, no domínio mais amplo da cultura, quanto, em especial, em relação com o cotidiano.

Considera-se, assim, que os domínios da cultura, embora tendam a se automatizar, estão articulados entre si e também vinculados às inflexões do mundo da vida. De modo semelhante, os gêneros discursivos produzidos nesses diferentes domínios podem ser distinguidos e nomeados, mas possuem estreitas ligações e características comuns. Relativamente estáveis, os gêneros são também flexíveis e dinâmicos. Entre eles, Bakhtin destaca o romance, gênero com maior plasticidade, capacidade de assimilar outros gêneros e acompanhar as mudanças e a diversidade do fluxo da vida.

Vê-se que, aqui, queremos ressaltar, além da distinção, também a relação, a articulação entre os domínios da cultura e entre os gêneros. É isso que nos vem à mente quando tomamos como objeto de estudo Mil rosas roubadas, de Silviano Santiago (2014), obra que parece testar e experimentar, de um lado, as fronteiras entre a vida, o conhecimento e a arte, e, de outro, os limites entre biografia, autobiografia e outros gêneros.

Acompanhamos, em Mil rosas roubadas, a voz de um eu narrador que rememora sua relação com Zeca, um amigo de adolescência: a circunstância em que o conheceu, o último encontro em que o visita em seu leito de morte, os afetos vivenciados, a empatia, os conflitos, a personalidade do amigo. Diferentes e 
Linha D'Água (Online), São Paulo, v. 30, n. 2, p. 113-128, out. 2017

numerosos elementos da história - principalmente, localidades, datas e referências culturais - provocam o leitor a sobrepor à figura do narrador - que não recebe um nome - o próprio Silviano Santiago, e, entre os que conhecem melhor a biografia do escritor, a relacionar o amigo com Zeca Jagger, pseudônimo de Ezequiel Neves, compositor e produtor cultural dos anos 1980. É dele, inclusive, a composição da canção "Exagerado", cantada por Cazuza, que traz, em um de seus versos, a expressão "mil rosas roubadas", e que ecoa no texto de Silviano Santiago.

A relação do narrador com o amigo é a principal relação eu/outro presente no romance. É ela o eixo que constitui toda a história. Em torno dela, são narrados, pelo recurso da memória, flashes, fases da vida dos dois amigos, mas mais acentuadamente, a do próprio narrador. Este se dedica a compor uma espécie de biografia do amigo, e, ao lembrar-se dele, ao tentar compreendê-lo, examina sua própria vida, encaminha uma autobiografia.

O leitor de Mil rosas roubadas, no entanto, não consegue imergir, por muito tempo, na história narrada. De quando em quando, é puxado à letra do texto, lembrado de sua condição de leitor, pelo narrador que põe em dúvida a adequação de suas lembranças e de sua própria escrita. A voz em primeira pessoa propõe-se a escrever a biografia do amigo, vê-se desviar em direção à autobiografia e, incansavelmente, segue, retorna, debate os rumos que percorre. Assim, à dramatização do eu em encontros e desencontros com o amigo, se junta o drama da escrita da memória, da confissão, da biografia, da autobiografia.

Com essa problematização que, explicitamente, opera das convenções da ficção, Mil rosas roubadas vincula-se ao que se tem designado metaficção, não um subgênero do romance, mas uma de suas tendências, tão antiga quanto ele, porém mais proeminente depois dos anos 1960 (WAUGH, 1993). O desvelamento na ficção de sua própria convencionalidade expõe sua organização e seu funcionamento, seu caráter de construção, que acaba por contaminar também a relação ficção/realidade. Por isso, a metaficção ocupa-se, prioritariamente, da exposição e desconstrução dos artifícios do realismo (WAUGH, 1993, HUTCHEON, 1991). A metaficção compreende a repercussão, na esfera literária, da percepção de que o mundo empírico é cognoscível apenas por meio do filtro da mente e da atividade humanas, de que somente se tem acesso a discursos sobre o mundo, de que a 
Linha D'Água (Online), São Paulo, v. 30, n. 2, p. 113-128, out. 2017

compreensão que se tem da realidade e da história é, portanto, sempre provisória. Nesse contexto, não há uma linguagem privilegiada, nem recursos mais adequados, o que explica a presença de várias linguagens, que competem entre si e se relativizam (WAUGH, 1993).

Silviano Santiago, além de escritor, é também professor e crítico literário. Não surpreende, portanto, que, ao tentar deliberadamente projetar-se na sua ficção, o próprio fazer criativo seja objeto de reflexão. Isso também acontece fora da ficção: no ensaio "Meditação sobre o ofício de criar" (2008), Santiago considera que, em seus últimos livros - entre os quais, certamente, incluiria Mil rosas roubadas -, realiza um "exercício da literatura do eu". Explica que acabou por adotar, para nomear seu trabalho, o termo autofiç̧ão, cunhado por Serge Doubrovsky, crítico e escritor francês, e incorporado por Vincent Colonna, crítico e historiador da literatura, mesmo considerando sua fiç̧ão do eu diferente da tratada pelos dois autores.

Embora venha sendo usado, e, inclusive, tenha entrado para o Larousse e para o Le Robert, como assinala o próprio Doubrovsky (2013), o termo autoficção não é uma unanimidade na crítica literária, nem em relação à sua pertinência ${ }^{1} \mathrm{e}$ nem mesmo em relação à sua definição. Doubrovsky (2013) descreve e explica o surgimento do termo, que filia ao pacto autobiográfico, estabelecido por Philippe Lejeune, segundo o qual deve haver homonímia entre o autor e o protagonista. Procedimento que, confessa, não adota em função de convenções literárias, mas, sim, em função de seu desejo de compartilhar com leitores suas experiências verdadeiramente vividas. Para Doubrovsky, contudo, a autobiografia é obra de figuras de importância e, então, prefere autoficção: “a forma pós-moderna da autobiografia. (...) Temos que encontrar uma escrita que corresponda a esta nova percepção de nós mesmos" (2013). ${ }^{2}$

Para ficarmos com os autores mencionados por Santiago, vejamos um trecho de Doubrovsky (2013), em que expõe seu entendimento da autoficção e o contrasta com o de Colonna:

1 Para Leyla Perrone-Moisés, não se trata de um novo gênero, mas o termo substitui, com eficácia, as perífrases "biografia romanceada", "ficção autobiográfica", "romance inspirado em fatos reais" (2016, p. 209).

2 No original: "la forme postmoderne de l'autobiographie. (...) Il faut bien trouver une écriture qui corresponde à cette nouvelle perception de soi-même".

MARCHEZAN, R. C.; PERNAMBUCO, J. Mil rosas roubadas, de Silviano Santiago, em 
Linha D'Água (Online), São Paulo, v. 30, n. 2, p. 113-128, out. 2017

\begin{abstract}
Vincent Colonna vê na homonímia (...) a maneira de inventar uma vida imaginária: está absolutamente no seu direito. Pessoalmente, eu vou em outra direção. A autoficção é o modo de tentar reaver, recriar, refazer, em um texto, em uma escrita, experiências vividas, em sua própria vida, que não são, de maneira nenhuma, uma reprodução, uma fotografia... É literalmente e literariamente uma reinvenção (Doubrovsky, 2013). ${ }^{3}$
\end{abstract}

Diferentemente de Colonna, que destaca a imaginação, Doubrovsky compromete-se a expor experiências vividas, que são retiradas de um diário das sessões com seu psicanalista. A reinvenção, para ele, fica entregue à linguagem.

Mesmo adotando o termo autoficção para nomear seu trabalho, Silviano Santiago não se interessa pela oposição vivido/imaginado, destacada por Doubrovsky e Colonna. Conforme declara no ensaio - e exercita em Mil rosas roubadas -, busca com seu exercício a "ressemantização do sujeito pelo sujeito" (SANTIAGO, 2008, 174), usando os termos de Foucault.

\title{
Biografia e autobiografia em Bakhtin
}

As (auto)biografias e os romances (auto)biográficos integram a reflexão de Bakhtin sobre as relações entre autor/herói (1997a), sobre o romance de Dostoiévski (1981) e sobre o desenvolvimento histórico do romance (1997b) ${ }^{4}$. Depreendem-se desses trabalhos, embora não seja seu objetivo principal, as características básicas das formas (auto)biográficas, e também as considerações acerca da "estilização da forma biográfica” (1997a). É nessa relação entre a forma biográfica ideal e sua estilização que seguimos analisando Mil rosas roubadas.

Em "O autor e o herói”, estudo em que se detém, mais demoradamente, na reflexão sobre a biografia e a autobiografia, Bakhtin as situa no domínio artístico,

3 No original: "Vincent Colonna voit dans I'homonymat (...) le moyen de s'inventer une vie imaginaire: c'est son droit absolu. Personnellement, je vais dans l'autre sens. L'autofiction, c'est le moyen d'essayer de rattraper, de recréer, de refaçonner dans un texte, dans une écriture, des expériences vécues, de sa propre vie qui ne sont en aucune manière une reproduction, une photographie... C'est littéralement et littérairement une réinvention".

4 Deve-se mencionar, ainda, no estudo do cronotopo no romance, a consideração da biografia e autobiografia antigas (BAKHTIN, 1988).

MARCHEZAN, R. C.; PERNAMBUCO, J. Mil rosas roubadas, de Silviano Santiago, em 
embora reconheça também a existência de uma forma científica para elas, com finalidade prática ou objetiva (1997a, p. 165), certamente, na qual o biógrafo se cerca de fontes diversas sobre o biografado e estabelece métodos de organização adequados à área.

Nessa obra, como assinala já seu título, o fio condutor das reflexões é o exame da relação entre o autor e o herói, realizado com base na relação eu/outro no domínio da vida. Estaria já, nessa obra, portanto, o germe da concepção dialógica da linguagem, que Bakhtin formularia depois ${ }^{5}$. No terreno da arte, a relação autor/ herói é especificada pelo princípio da exterioridade. O autor ocupa uma posição exterior ao herói: o ato estético pressupõe, então, duas consciências. Quando autor e herói coincidem ou quando não há herói, não há acontecimento estético, mas, sim, acontecimento ético ou cognitivo.

Bakhtin localiza o surgimento da biografia e da autobiografia, entre as quais não distingue uma fronteira nítida (1997a, p. 165), no desenvolvimento das formas da confissão, quando o eu deixa de se dirigir a Deus, quando não está mais entregue inteiramente ao ato de contrição, pode colocar-se de fora, e, como um outro, contemplar sua vida.

O romance autobiográfico solicita que o autor se distancie da própria vida e, assim, tenha um excedente de visão, contemple-a de fora. $\mathrm{O}$ autor torna-se um objeto para si mesmo e, desse modo, coloca-se em condições de atribuir valores à vida. Se não se deslocar do ato de viver a sua própria vida, não conseguirá criar efetivamente o objeto estético. Estará apenas descrevendo os momentos de uma vida. É preciso que o eu saiba distanciar-se da própria vida, para vê-la com outros olhos que não os seus, olhos outros que em seus olhos olham.

Nas palavras de Bakhtin:

Entendo por biografia ou autobiografia (narrativa de uma vida) uma forma tão imediata quanto possível, e que me seja transcendente, mediante a qual posso objetivar meu eu e minha vida num plano artístico. (...) A coincidência de pessoas na vida, entre a pessoa de que se fala e a pessoa que fala, não elimina a distinção existente dentro do todo artístico (...) (BAKHTIN, 1997a, p. 165).

5 Estamos concordando com Holquist (1993). 
Há, portanto, duas consciências: a do autor e a do seu objeto, no caso, o herói biografado, e esse pode ser tanto um outro, quanto, em se tratando da autobiografia, ele próprio. Por isso mesmo, conforme a citação acima, a (auto)biografia é uma forma "tão imediata quanto possível", é "a forma mais realista". Nela, a mediação do autor, responsável pelo acabamento artístico, é menos pronunciada.

Os valores biográficos são menos transcendentes à consciência do outro, são valores comuns à vida e à arte. $\mathrm{O}$ que particulariza a relação autor/herói na (auto) biografia é, sem prejuízo de uma exterioridade do autor, a sua proximidade tanto física quanto axiológica, em relação ao herói:

O autor da biografia é o outro possível, cujo domínio sobre mim na vida admito com a maior boa vontade, que se encontra ao meu lado quando me olho no espelho, quando sonho com a glória, quando reconstruo uma vida exterior para mim; é o outro possível que penetrou em minha consciência e que com frequência me governa a conduta, o juízo de valor e que, na visão que tenho de mim, vem colocar-se ao lado de meu eu-para-mim (...) (BAKHTIN, 1997a, p. 166).

Em análise histórica da biografia romanceada/do romance biográfico, Bakhtin localiza (e exemplifica) dois tipos básicos: o que pertence à aventura heróica e o sócio-doméstico. O que distingue os dois tipos são valores biográficos diferentes, e assim são porque compreendem diferentes perspectivas sobre o mundo. No primeiro tipo, os valores que regem o herói são os da aventura heróica, a glória, o reconhecimento. São valores individualistas, mas são conduzidos pelo outro, para o outro, para que se reconheça seu lugar heróico na história, na humanidade. Os valores do segundo tipo não visam à inscrição na história do homem, mas na sociedade. Estão relacionados à família, à vida social e privada. Aqui, não há grandes ações, o protagonista vive o cotidiano e suas principais atividades são observar e narrar.

Bakhtin também se serve dessa reflexão sobre os valores biográficos, em Problemas da poética de Dostoiéruski, justamente para mostrar que eles não têm importância no romance de Dostoiévski, em que a temporalidade que se privilegia é a da simultaneidade, e não a da duração histórica e biográfica, e em que os heróis "não têm biografia no sentido do ido e do plenamente vivido" (1981, p. 23), antes 
"sonham e desejam ardentemente personificar-se, incorporar-se ao tema normal da vida" (1981, p. 87).

Em outro trabalho, visando ao exame do desenvolvimento do romance do qual origina o romance de educação, Bakhtin (1997b) retoma as características básicas do romance biográfico do segundo tipo, mencionado acima, seu enredo, a imagem de seu herói e sua temporalidade: o percurso típico de uma vida - o nascimento, as diferentes fases de desenvolvimento, o trabalho, o casamento, a morte - ordena o enredo e demarca uma temporalidade de caráter, principalmente, biológico, em que o tempo histórico aparece apenas de modo acessório, funcional. A imagem do herói é criada nesse enredo, do qual se destacam "os resultados objetivos", seus sucessos e fracassos. Bakhtin nota ainda que os traços positivos ou negativos o herói já os tem desde o início. Para ele, no romance biográfico, "o homem permanece inalterado" (BAKHTIN, 1997b, p. 233).

Inserida no exame do desenvolvimento histórico das obras literárias, a reflexão de Bakhtin sobre a (auto)biografia assinala seu surgimento, como vimos, e segue mostrando sua transformação: o mundo biográfico - em que autor e herói compartilham valores semelhantes - começa a ruir, quando o autor se distancia do herói biografado, quando, entre autor e herói, se interpõem mediações, perspectivas, quando "o autor adquire espírito crítico" (1997a, p. 176). Para Bakhtin, é esse autor crítico, cético em relação aos valores do herói que realiza a estilização da forma biográfica (1997a), ao interpor outros valores, inclusive estéticos, aos valores da biografia.

Como a noção de paródia, também a de estilização (e aqui estamos nos baseando em Bakhtin, 1981) vincula-se à dupla orientação da palavra, que se volta para o objeto do discurso e para o discurso do outro, mas, diferentemente da paródia, a estilização não é hostil ao discurso do outro:

A estilização pressupõe o estilo, ou seja, pressupõe que o conjunto de procedimentos estilísticos que ela reproduz teve, em certa época, significação direta e imediata, exprimiu a última instância da significação. (...) $\mathrm{O}$ estilizador usa o discurso de um outro como discurso de um outro e assim lança uma leve sombra objetiva sobre esse discurso. (...) o importante para o estilizador é o conjunto de procedimentos do discurso de uma outra pessoa precisamente como expressão de um ponto de vista específico. Ele trabalha com um ponto de vista do outro. Por 
isto uma certa sombra objetivada recai justamente sobre o ponto de vista, donde resulta que ele se torna convencional (1981, p. 164).

$\mathrm{Na}$ estilização, portanto, a duplicidade, o cruzamento de perspectivas continua perceptível, não há fusão das vozes, como na imitação. No caso que nos interessa aqui, para a leitura de Mil rosas roubadas, a estilização mira o ponto de vista (auto)biográfico, mas não se apropria dele sem reservas. A distância que assume em relação aos valores (auto)biográficos torna-os convencionais, e, portanto, não mais adequados, apreciados, dignos de todo o crédito. Somente são adotados, então, de modo estilizado, em que aparecem como sendo valores de um outro, de uma outra época.

$\mathrm{Na}$ sua estilização, Silviano Santiago relativiza o ponto de vista e os valores (auto)biográficos, o que aparece, programaticamente, em “Meditação...”:

Inserir alguma coisa (o discurso autobiográfico) noutra diferente (o discurso ficcional) significa relativizar o poder e os limites de ambas, e significa também admitir outras perspectivas de trabalho para o escritor e oferecer-lhe outras facetas de percepção do objeto literário, que se tornou diferenciado e híbrido. Não contam mais as respectivas purezas centralizadoras da autobiografia e da ficção; são os processos de hibridização do autobiográfico pelo ficcional, e vice-versa, que contam. Ou melhor, são as margens em constante contaminação que se adiantam como lugar de trabalho do escritor e de resolução dos problemas da escrita criativa (SANTIAGO, 2008, p. 174).

Conforme se antecipou mais no início deste texto, e reitera-se na citação acima, para Silviano Santiago, a contenda entre o vivido/imaginado ficou para trás. O escritor busca a "verdade poética", e considera-se "um falso mentiroso" (SANTIAGO, 2008). Em Mil rosas roubadas, Santiago busca, com a relativização/hibridização do autobiográfico e do ficcional, explorar os sentidos do objeto literário e, com eles, os sentidos do eu. 
Linha D'Água (Online), São Paulo, v. 30, n. 2, p. 113-128, out. 2017

\section{Os valores (auto)biográficos no texto Mil rosas roubadas}

O romance é o objeto de estudo privilegiado por Bakhtin, que encontra na sua inadequação aos padrões do cânone literário tradicional o próprio argumento para sua definição. Fora das regras canônicas, o romance é o gênero que representa, por excelência, as forças centrífugas da modernidade. Acompanha o fluxo da vida e, desse modo, sempre inacabado, absorve as mais diversas inflexões da vida social e todo o seu plurilinguismo, este, por princípio, ausente dos gêneros literários canônicos. Sem moldes rígidos, o romance interage com outros gêneros, estiliza-os e luta, inclusive, consigo mesmo nas etapas de sua evolução.

$\mathrm{Na}$ contemporaneidade, intensificam-se as forças centrífugas da modernidade e, com elas, as transformações na construção do romance, da obra literária. O que se realiza em Mil rosas roubadas, não pontualmente, mas em sua totalidade. As convenções da ficção são, explicitamente, problematizadas; o tema central do eu não desenvolve sem ressalvas os valores e o ponto de vista (auto)biográfico, caracterizados no item anterior. $\mathrm{O}$ narrador investiga sua própria escrita, avalia sua adequação, pondera sobre seu estatuto de biografia, de autobiografia, sempre a considerar também o papel do seu leitor, e a interpelá-lo:

(1) É o caso de se perguntar quem derrota quem na hora da escrita da biografia: vence a dama ignorância, que ignora e imagina os fatos vividos pelo retratado, ou a dama admiração, que endeusa o ser humano biografado? Uma senhora não deve derrotar a outra senhora (SANTIAGO, 2014, p. 22). ${ }^{6}$

(2) Todo biógrafo não será monstruoso por definição? Cada um ao seu jeito, não será cego de um olho e estrábico do outro? Não enxerga o que pode, não reproduz o que quer e não engendra só o que é conveniente? (p. 24).

(3) A escrita biográfica não comporta balbucio nem titubeio. Seu exercício flui naturalmente do próprio sangue de quem escreve. Inunda o coração, deságua na mente e, ao bater à porta das teclas do computador, já delegou às mãos o direito ao julgamento peremptório (p. 67).

6 Daqui em diante, informamos apenas a paginação de Santiago (2014).

MARCHEZAN, R. C.; PERNAMBUCO, J. Mil rosas roubadas, de Silviano Santiago, em 
(4) Ao relatar nosso primeiro encontro, omiti parte significativa da primeira conversa. Não tenho o direito de esconder do leitor passagens esclarecedoras do nosso relacionamento, em particular as que tocam em diferenças sensíveis de temperamento, de conhecimento artístico e de visão de mundo. (...) Volto atrás e me corrijo. Só assim me absolvo do deslize cometido e espero ganhar o perdão do leitor (p. 69).

(5) Como pretendo manter a baliza da infidelidade do narrador no lugar a que ela tem direito, compete ao leitor introduzir a fala surripiada no lugar que lhe é determinado pela cronologia. Preencha o vazio, por favor (p. 71).

(6) Fui deixando a biografia do amigo derrapar na autobiografia do historiador de plantão (p. 205).

(7) Ser coroinha sincero ao pé do altar da biografia, caro leitor e padre confessor, é minha negação e única forma possível de reafirmar postumamente o valor do Zeca (p. 262).

Os trechos acima, selecionados entre tantos outros, expõem as próprias convenções da escrita (auto)biográfica. O trecho 3 parece descrever e assumir uma prática biográfica “imediata", “ingênua” (BAKHTIN, 1997a), que não se cerca de uma reflexão sobre si mesma, mas, ao mesmo tempo, em outros momentos, é outra a direção da escrita: a ser composta tanto com a ignorância e a imaginação, quanto com a admiração (trecho 1); tanto com o que se pode, quanto com o que se quer enxergar (trecho 2). E não é o caso de revelarmos, aí, uma contradição. O próprio narrador já nos dissuade da ideia: "Sou contraditório. Fomos [Zeca e eu] contraditórios na manifestação do afeto. Por que o deixarei de ser agora?” (p. 10).

O trecho (6) é um de vários momentos em que o narrador parece flagrar-se em meio à ausência de limites entre a biografia e a autobiografia (tal como assumido teoricamente no nosso item anterior). Os demais trechos exemplificam a inserção que o narrador faz da figura do leitor: para mostrar preocupação com ele e seu direito ao relato preciso (trecho 4), ou, ao contrário, para atribuir a ele a tarefa de preencher os vazios que o narrador tem o direito de deixar (trecho 5) e, ainda, para fazer-lhe um chamamento, e lhe atribuir também o papel de padre confessor (trecho 7).

As características do segundo tipo de (auto)biografia, assinaladas no item anterior, estão, de um modo geral, presentes em Mil rosas roubadas. A (auto)biografia 
lida com valores comuns à vida e à arte; nesse sentido, o autor, portador da forma artística, e o herói tendem a aproximar-se. Ao problematizar e meditar sobre a prática da escrita (auto)biográfica, Mil rosas roubadas rompe com esse caráter "imediato", "realista". A despeito dos recursos, já mencionados, que aproximam Silviano Santiago e o narrador - vida e obra -, a reflexão sobre a prática da escrita interpõese como mediadora, a abalar as fronteiras "realistas" entre a vida e a arte, a minar os dispositivos dos gêneros naturalizados, automatizados.

$\mathrm{Na}$ obra analisada, o tempo biológico de uma vida é explorado, e o tempo histórico lhe é apenas secundário, pano de fundo das vidas narradas. O percurso típico de uma vida organiza o enredo, mas, a começar mesmo por aí, a obra altera o modelo. Prioriza o percurso entrelaçado de duas vidas: a do narrador e a de seu amigo Zeca. O herói biografado é ora o eu, ora o amigo; ou melhor, não se trata de alternância, são dois os biografados pela voz do eu: o eu e o outro. Um não existe sem o outro. Por isso mesmo, o questionamento que o próprio narrador faz sobre seu texto, que o percebe mover-se entre a biografia e a autobiografia.

A duplicidade de heróis e o entrelaçamento de suas vidas rompem com a forma biográfica típica (BAKHTIN, 1997a). As principais atividades do narrador autobiografado, que também realiza a biografia do amigo, não se restringem à observação e narração. Não temos, em Mil rosas roubadas, um narrador que, com empatia, penetrou a consciência do herói e o acompanha de perto. Esse autor "ingênuo" (Bakhtin, 1997a) da forma biográfica típica é substituído por um autor "crítico" (Bakhtin, 1997a), que examina e avalia o que narra, um autor "cético", cujas incertezas sobre o que narra misturam-se às incertezas sobre a vida. Autor crítico que, no entanto, não possui um ponto de vista definido a balizar o herói, não possui valores sólidos a permear sua distância do herói. Sem acesso certeiro ao herói, mas, mesmo assim, na sua busca, o autor dedica-se a cruzamentos de perspectivas possíveis, de relatos alternativos, e, desse modo, encontra sentidos para o herói, ressemantiza o eu.

Sempre por meio da voz desse eu narrador, há o nascimento, as experiências que Zeca e o narrador vivenciaram na adolescência, a família, a escola, a mineiridade, a igreja - instituições nas quais e também contra as quais se constituíram -, a vida adulta, as escolhas culturais, a profissão, o trabalho e a morte do amigo. Fora 
do relato típico, no entanto, o nascimento desses heróis é o primeiro encontro: "Nascemos um para o outro aos dezesseis anos de idade, em Belo Horizonte, nos idos de 1952" (p. 7). "Desde nosso primeiro encontro, eu me senti avistado, perscrutado, lido, distinguido, separado e eleito por ele” (p. 103).

A obra, ou melhor, a "biografia" do amigo que o narrador, já em casa escreve, tem início na última vez que o vê em seu leito de morte. Está diante do amigo e observa com distanciamento o corpo inerte, "envolto pela mortalha dos lençóis", torturado pelos aparelhos que, artificialmente, o mantêm respirando; em meio à sobreposição de tempos e cenas - de um filme, de uma pintura, de um livro, de lembranças do passado, da enfermeira que surge para assistir ao paciente -, interroga-o e interroga-se sobre sentimentos e emoções. "Fôramos inicialmente apaixonados, depois amigos e, finalmente, cúmplices” (p. 225).

Nos primeiros enunciados da obra, a constatação: "Perco meu biógrafo" (p. 7). "Ele me conheceu como eu não me conhecia e eu (...) não o conheço por inteiro" (p. 33). Mesmo assim, promete escrever a biografia do amigo. Somente ele poderia fazê-lo. Estiveram mais distantes depois dos anos 1980, mas o narrador o fizera presente vinte e quatro horas por dia, "para ver-me melhor" (p. 32): “(...) eu fazia de conta que ele estava presente ao meu lado, ali - em algum lugar preciso e imaginário (...) maneira de estar sempre com ele sem estar" (p. 25-6).

O relato biográfico - termo que o narrador parece preferir para nomear sua escrita - prossegue e, mesmo com dúvidas, hesitações, revisões, reafirmações, configura a imagem dos dois heróis. $\mathrm{Na}$ composição da qual, não recebem relevo os "resultados objetivos" obtidos durante a vida - também em desvio da tipicidade da biografia apontada no estudo de Bakhtin. A profissão, os sucessos e os fracassos dos dois amigos não estão para registrar feitos e resultados objetivos, mas para compor a relação entre os dois amigos e a avaliação recíproca que faziam de si: o eu, professor e pesquisador universitário de história do Brasil, que, para Zeca, preferiu a estabilidade à vida; Zeca, artista e jornalista cultural.

Ele é amigo, não é modelo. Sou sincero. Ele não é profissional liberal, é biscateiro por opção. Não é imitável, é invejado. Está solto, mas tão preso quanto eu às convenções físicas da vida diária. Eu elegi a pressa e a rotina da linha reta, ele 
vai por caminhos cansativos e pericêntricos (...) Abusei da condição de professor universitário e negligenciei os percalços do ofício de viver? (p. 163).

Bakhtin lembra-nos que, no romance biográfico típico, as realizações do herói são relatadas, mas ele próprio permanece o mesmo, "inalterado". Em Mil rosas roubadas, mais ao final do relato, o eu se diz modificado. Agora sabe o que não sabia antes, vê sua vida como não via antes:

Diante da doença dolorosa e fatal, caí na armadilha armada por mim e pelo destino. Num relâmpago de lucidez, os feitos e a vida do Zeca se voltaram contra mim. Enxergava-me de perspectiva diferente e preocupante. Enxerguei-me então tal como fui e sou. Professor aposentado de história do Brasil numa universidade de província brasileira. Um cara sem importância coletiva (p. 262).

Aprendia, ao escrever sobre a vida alheia. Ao reler a parte mentirosa do relato sobre a vida alheia, aprendi. Aprendendo, aprendi o modo como tinha aprendido a mentir sobre a minha vida. Fui aprendendo a me acautelar diante do que escrevia e a me reconhecer lá dentro dos próprios buracos que se abriam no texto e clamavam por revisão (p. 264).

Tal como o relato singular do nascimento dos amigos, também o da morte orienta nossa análise. A escrita da "biografia", prometida diante do amigo moribundo, termina. E, com ela, a morte do eu: "Sentado diante do computador, não sonho mais. A realidade da nossa vida em comum, da minha vida singular está tensa e imóvel na folha de papel. Petrificada, imutável. Morta" (p. 276).

Para o narrador, a morte do amigo e a escrita da biografia compõem uma “armadilha", que o captura e lhe provoca a lucidez, a sinceridade. De biógrafo da vida alheia, acaba objeto de sua própria biografia. Diante do amigo, o eu revela-se outro. Sem onisciência, nem onipotência, o narrador, somente ao final, tem sua verdadeira imagem configurada pelo acontecimento da escrita.

Nasceram juntos, morreram juntos também. $O$ narrador continua vivo, mas é outro agora. A escrita não é, portanto, considerada apenas um meio, um instrumento. A relativização de diferentes linguagens, o cruzamento de diferentes verdades são os 
Linha D'Água (Online), São Paulo, v. 30, n. 2, p. 113-128, out. 2017

procedimentos possíveis da atividade criadora, a condição para atribuir sentidos à vida. Mil rosas roubadas que, agora, existe, dá conta da vida dos dois heróis.

\section{Referências}

BAKHTIN, M. O autor e o herói. IN: BAKHTIN, M. Estética da criação verbal. Tradução a partir do francês por Maria Ermantina Galvão G. Pereira; revisão da tradução Marina Appenzeller. 2. ed. São Paulo: Martins Fontes, 1997a. p. 23-220.

BAKHTIN, M. O romance de educação na história do realismo. IN: BAKHTIN, M. Estética da criação verbal. Tradução a partir do francês por Maria Ermantina Galvão G. Pereira; revisão da tradução Marina Appenzeller. 2. ed. São Paulo: Martins Fontes, 1997b. p. 221-234.

BAKHTIN. M. Formas de tempo e de cronotopo no romance (Ensaios de poética histórica). IN: BAKHTIN. M. Questôes de literatura e de estética. A teoria do romance. Trad. Aurora Fornoni Bernardini et al. São Paulo: Unesp, Hucitec. 1988. p. 211-362.

BAKHTIN, M. Problemas da poética de Dostoiérski. 4. ed. Trad. Paulo Bezerra. Rio de Janeiro: Forense Universitária, 1981.

DOUBROVSKY, S. “Les points sur les 'i”, Item. Mis en ligne le: 27 juin 2013. Disponível em: http://www.item.ens.fr/index.php?id=578883 .

HOLQUIST, M. Foreword. In: BAKHTIN, M. M. Toward a philosophy of the act. Translation and notes by Vadim Liapunov; edited by Vadim Liapunov and Michael Holquist. Austin, TX: Texas University Press: 1993. p. vii-xv.

HUTCHEON, L. Narcissistic Narrative: the metafictional paradox. London: Routledge 1991.

PERRONE-MOISÉS, L. Mutaçôes da literatura no século XXI. São Paulo: Companhia das Letras, 2016.

SANTIAGO, S. Mil rosas roubadas. São Paulo: Companhia das Letras, 2014.

SANTIAGO, S. Meditação sobre o ofício de criar. Aletria: Revista de Estudos de Literatura, v. 18, jul./dez. 2008. 
Linha D'Água (Online), São Paulo, v. 30, n. 2, p. 113-128, out. 2017

WAUGH, P. Metafiction: the theory and practice of self-conscious fiction. London; New York: Routledge, 1993.

Recebido em 8/06/2017. Aprovado em 31/07/2017. 